\title{
Tradition and Modernity in Cameroon: The Confrontation between Social Demand and Biomedical Logics of Health Services
}

\author{
Gervais Beninguisse' and Vincent De Brouwere ${ }^{2}$
}

\begin{abstract}
This paper examines the cultural acceptability of biomedical obstetrical services and care across an anthropological literature review and a qualitative survey carried out in North Cameroon. The results reveal that cultural acceptability of biomedical services is impaired by a series of requirements such as a too early first prenatal visit; use in common of delivery rooms, wards and obstetrical tools; the absence of traditional healing like massage after delivery; refusal to hand over the placenta and umbilical cord to the family; and hindering the presence of family members during delivery. These evidences support a transition from normative medical system to an efficient and flexible medical system related to the expectations of the population established with its participation. This is commonly called patient-centred care. (Afr Jeprod Health 2004; 8[3]:152-175)
\end{abstract}

\section{RÉSUMÉ}

Tradition et modernité au Cameroun: le conflit entre l'exigence sociale et les logiques biomédicales des services de la santé. Cet article étudie l'acceptabilité culturelle des services et des obstétriques biomédicaux à travers l'analyse littéraire anthropologique et une enquête qualitative menées au nord du Cameroun. Les résultats montrent que l'acceptabilité culturelle des services biomédicaux est entravée par une série d'exigences telle une première visite prénatale précoce, l'emploi en commun des salles d'accouchement, des salles d'hôpital et d'outils obstétriques, l'absence du traitement traditionnel comme le massage après l'accouchement; le refus de rendre la placenta et le cordon ombilical à la famille ; et entravant la présence des membres de famille pendant l'accouchement. Ces évidences appuient une transition depuis un système médical normatif à un système médical efficace et flexible, ayant un rapport avec l'attente de la population établie avec sa participation. On appelle ceci communément le soin centré sur la patiente. (Rev Afr Santé Reprod2004; 8[3]:152-175)

KEY WORDS: Tradition, modernity, obstetrical services, care, Cameroon

Groupe de Recherche Interdisciplinaire en Santé (GRIS) and Unité de Santé Internationale, University of Montreal, Edifice SaintUrbain, 3875 rue Saint-Urbain 5e étage, Montreal, Quebec, H3W 1V1, Canada. Fax: (1)514-4127108; E-mail: gervais.beninguisse@umontreal.ca ${ }^{2}$ Vincentde Brounere,Professor of Public Health, Institute of TropicalMedicine, Antwerp, Belgium. E-mail:vdbroun@itg.be

Correspondence: Groupe de Recherche Interdisciplinaire en Santé (GRIS) and Unité de Santé Internationale, University of Montreal, Edifice Saint-Urbain, 3875 rue Saint-Urbain 5e étage, Montreal, Quebec, H3W 1V1, Canada. Fax: (1)514-4127108; E-mail: gervais.beninguisse@umontreal.ca 


\section{Introduction}

All African societies possessed and many of them are far from having lost them specific models and practices relating to pregnancy and childbirth. These traditional models and practices give an explanation of conception, the evolution of pregnancy and childbirth, which is consistent with the life representations of the ethnic group. They also define the way in which pregnancy and childbirth are to be protected. The pregnant woman observed alimentary and behavioural prohibitions and prescriptions gave birth at home, alone or with the help of a matrone (traditional birth attendant) or a relative. A network of mutual aid and psychological support between the women and their family governed this pattern of maternity, characterised by simplicity of technique and pharmacopoeia and rudimentary working equipment.

With the scientific and technical progress, which has marked the 20th century in the biomedical field and has favoured the emergence of what some have called the "biomedical paradigm" or the "ideology of risk", there are other alternatives. In addition to the traditional formula, it is now possible to have recourse to the biomedical apparatus of obstetric services (hospital, clinic, dispensary, health centre, etc), with care from qualified health personnel (doctor, midwife, nurse, etc). Nowadays most developing countries are characterised by a plurality of traditional and modern medical systems and subsystems. An understanding of the underlying logics will make it possible to apprehend better the mechanisms that are at the basis of a demand for obstetric services and care.

Starting from a confrontation between traditional and biomedical logics, this article seeks to identify some of the implications on the demand for obstetric services and care in the form of hypotheses.

\section{Methods \\ Literature Review}

The literature is based on scattered writings buried in monographic works on particular ethnic groups in Cameroon dealing with general subjects such as sexuality, social life and organisation, procreation, etc. The scientific study of representations and customs relative to the expectation and coming into the world of children has barely begun. Between 1940 and 1996 there were only 23 publications on the subject. Moreover, a number of observations and reservations need to be made on these works.

Many of these works relate to a relatively distant past, but nevertheless the descriptions of customs and traditions are still up-to-date, even if in contact with western cultural

By models and practices must be understood the complex of techniques, beliefs and knowledge of the traditional health system peculiar to a given community, which looks afterpregnancy and childbirth.

That is to say, a complex of discourses based on the notion of risk which claim to construct objective conditions of danger in order to deduce from them types of intervention according to the medical model. ${ }^{33}$ 
models (school attendance, Christianity, modernity, etc.), some practices are gradually falling into disuse. We shall speak of these models and practices in the present tense, without necessarily implying that they are to be found at the present time.

Most of the authors of these works are foreign ecclesiastics or missionaries. Since they are strangers to the culture they are investigating it is not always easy for them to interpret, understand and faithfully reproduce without error or aberration the lexical and anecdotal nuances of the idioms, which are so numerous in the language of the people they are dealing with, particularly when they are concerned with subjects as emotional as those relating to sexuality and reproduction. It may thus be feared that their writings have left free rein to arbitrary prejudices, as Laburthe-Tolra ${ }^{1}$ notes, following Tessmann ${ }^{2}$ : their frequent inability effectively to judge freely and present the facts in a purely scientific manner, without tendentious nuances, prejudices the value of their studies.

Moreover, since these works were not specifically undertaken for the study of cultural aspects relative to pregnancy, they frequently remain superficial. The difficulty of describing symbolic ' representations, customs and practices relative to pregnancy and childbirth is not entirely attributable to the observers: it is also due to their complex and sometimes esoteric nature.

In spite of their limitations, these works actually are the only basic material currently available for any study of pregnancy representations in Cameroon.

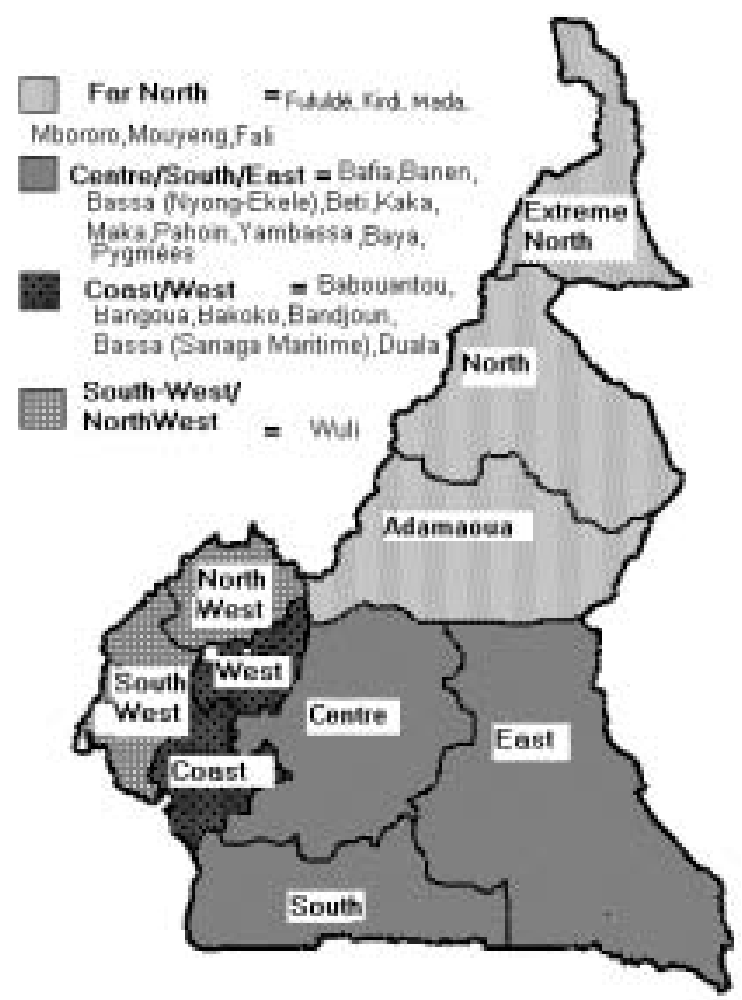

Figure 1 Geographical Distribution of the Ethnic Groups

\section{The Qualitative Survey}

The qualitative survey was carried out in 1997 in the form of group discussions. The objective was to examine women's perceptions of traditional and biomedical systems of obstetric services and care in a particularly unfavourable epidemiological context. The region of North Cameroon is the worst from the point of view of neonatal mortality, availability of health services and the use biomedical obstetric services. ${ }^{3}$ The methodology of the survey was simple. The way was prepared for it through the traditional authorities (village and district chiefs) by means of meetings for giving information and explanations to traditional 
birth attendants, their patients and their partners. Introduction of the survey to traditional authorities was facilitated through accompaniment of a well-known member of staff of the local obstetric services (a midwife or a nurse) and a guide who also acted as a translator and interpreter. The discussions were carried on with two categories of informants: (i) traditional birth attendants; and (ii) the clients, i.e. women who had given birth at least once with the help of traditional birth attendants and some who had given birth at least once in hospital.

In order to take part in these discussion groups the only requirement was to be a traditional birth attendant in active practice or a client and to be ready to answer questions. We recorded no refusals. A programme of discussions was prepared in advance. It covered three main themes: (1) the role of the traditional birth attendant and his/her social representation; (2) opinions on the motivations for the preferential choices in the care of pregnancy and delivery; and (3) opinions on the conditions of work and quality of care by the various providers of care.

The application of the programme of discussions varied from group to group according to the interest of members of the group in the themes under discussion. In general, the atmosphere of the groups was relaxed, making it possible to go thoroughly into the subjects. The average length of the discussions was two hours. Written notes were taken and the discussions were also recorded on audio tapes. Altogether four group discussions were carried out in the villages of Wak, Karnanga, Garoua and Ngaoundéré, with 24 members: eight female traditional birth attendants from the villages of Wak and
Karnanga; two male birth attendants from Wak and Karnanga; eight female birth attendants from Ngaoundéré; three clients of traditional birth attendants; and three clients of the Garoua hospital centre.

\section{Results}

The Social Construction of Pregnancy in Cameroon: Traditional Knowledge, Physiology and Biological Mechanisms of Conception

Preventive behaviour of a gestating woman depends in part on her knowledge of the physiology of her organs of reproduction and the biological mechanisms of conception. This determines her ability to identify and detect her pregnancy at an earlier or later stage. Beliefs pertaining to the physiology of conception are useful here to the extent that they make it possible to better understand the logic on which preventive behaviour is based.

Conception is seen in most Cameroon ethnic groups as the result of a mingling, within the vaginal orifice, following a sexual relationship, between the fertilising male seed (sperm) and female menstrual blood. For this mingling to produce fertilisation it must take place at an ideal moment, which varies between ethnic groups. Among the Beti ${ }^{4,1}$ it is believed that fertilisation cannot take place while the woman's menstrual blood is still fresh (that is, when it is flowing), for that is a clear sign of the transgression of the sexual prohibition during menstruation. It is preferable to wait until the end of menstruation, when the menstrual blood remaining in the vaginal conduit is partly dried, so that the mingling of sperm and female blood may lead to the formation of the 
embryo. Moreover, the child will be all the more vigorous if the sperm and female blood meet at a better time, that is, after menstruation. Among the Yambassa (Begunu tribe $)^{5}$ the chances of conceiving are believed to occur just before menstruation or just after above all not during menstruation, for there is then a risk of violent headaches, which would hinder any later fertilisation. It is thought that just before menstruation the vaginal orifice combines all the conditions necessary for fertilisation. Similarly, after menstruation the vaginal orifice, having been emptied of bad blood, is ready to receive a pregnancy. Among the Bassa ${ }^{6}$, for fertilisation to take place it must occur in the middle of the cycle and after menstruation (about two weeks), but compatibility of blood between the parents is indispensable. This compatibility is determined a posteriori when there has been a failure to fertilise after a sexual act performed in the middle of the cycle.

Menstruation is the necessary outflow of blood that has become impure and even harmful; it has been unable to contribute to the formation of the embryo as a result of being deprived of its fertilising force. Among the Bassa, ${ }^{6}$ a witch-doctor could use it to bring on evil spells such as barrenness in the woman. It is necessary, therefore, to be prudent during the menstrual period particularly through careful and discreet intimate hygiene.

Sperm, also known as "sign of life", "virile fertilisation force", "white blood", "man's blood", etc, is a liquid derived from male blood, produced in the lumbar area and stored in the testicles. It is evacuated from the testicles following the warming up of the body caused by sexual excitement. Sperm is in principle always fertilising. In the event of a failure to fertilise, the fault is most likely to be found in the woman. She will be invited in the first place to confess any transgression of prohibitions or to admit her involvement in sorcery and then subjected to therapeutic treatment by drugs and/or ritual at the hands of a soothsayer/healer. ${ }^{1,4,5,7}$ Since sperm is destined to give life, it is made sacred to the point that it is not permitted to spoil it by diverting it from the vaginal orifice, its ultimate destination, by masturbation or any other contraceptive procedure (such as the use of condom). In addition to this efficiency in the biological process, sperm is recognised as having the virtue of nourishing, supporting and promoting the development of the fetus. Accordingly, sexual relations will be continued during gestation and interrupted at a certain level of development of the fetus, varying between seven and eight months of pregnancy, in order not to "soil" the infant with deposits of sperm that would make it viscous or leave it with a cold at birth.

It is the "children's cords" (the ovaries) that permit the secretion of female menstrual blood and ensure its transmission into the vaginal orifice to leave room for the encounter with seminal liquid. ${ }^{1,4,8}$ From this encounter are formed the fetus (which is still only a paste or a concentration of blood), the "belly water" (amniotic fluid) and viscous matters. For this purpose a certain time during which there is an absence of periods (amenorrhoea), varying according to ethnic group, must be observed. Among the Bamiléké (Babouantou tribe), it is at least two lunations (two months). ${ }^{9}$ At the end of a month of amenorrhoea some women, for example, the Bassa, ${ }^{6}$ may feel the gurgling of the fetus in formation above the pubis or in the right iliac fossa.

The mingling of the sperm and female blood during the ideal period for conception, 
even in a physiologically fertile woman, does not necessarily lead to fertilisation. This mingling must first have been blessed by the transcendent and divine powers: this is the spiritual or mystic dimension of physiological paternity. For from the moment the physiological mechanisms of conception are initiated the influence of God, ancestors and earth spirits is recognised. Conception then appears as the result of copulatory action by the parents, favoured by the providential action of transcendental forces. ${ }^{1,4,10,11}$

\section{Intrauterine Life}

Most popular traditions estimate the duration of a normal gestation at between eight and nine lunations. When it is more than nine lunations it is thought that the child is sleeping, either because it thinks that the conditions required are not yet in place, or because God or the transcendental powers have willed it thus, or because the woman is the victim of sorcery or mischance. Among the Boubouantou, however, the length of gestation depends on the sex of the fetus and on whether or not it is twins. It is under nine months for girls, nine months for boys and over nine months for twins. The best documented illustration of the stages in the development of the fetus is given by Daniel ${ }^{6}$, Ombolo $^{4}$ and Onana Badang for the Bassa, Beti and Yambassa. The fetus passes through the following stages:

During the first two moons without periods the embryo is still in the mollusc phase, in the form of a small lizard. It is described as "a quarter of a moon rounded at one end with a kind of tail at the other end". During the period the seminal liquid and the female blood are mingling, the woman suffers malaises such as fatigue, nausea and vomiting mainly in the morning, frequent cravings for sleep, a change in the pigmentation of the breasts, etc, which are signs of a possible intrauterine life. Nevertheless, it is necessary to be sure that there is in fact intrauterine life. Towards the third moon the limbs become more distinct and resemble small buds; the arms, then the legs. Between the fourth and fifth months all the limbs appear and develop further, and the child's sex can be recognised particularly from its position, its movements and certain physical signs. At this period the woman regularly feels capricious cravings. In the sixth month the eyes, some hair and just the roots of the nails can be seen. In the seventh month, with the appearance of the nails, the child is completely formed. Sexual relations may now become less frequent, finally ceasing at about the eighth month, and the time has now come to prepare for the birth.

Throughout these stages the child leads a full intrauterine life. It usually occupies a stretched out position along the pelvis and makes movements, which are felt by the woman. These movements are frequently interpreted either as "journeys" or as "fits of anger or signs of a misfortune, which is latent in the family" (when they are particularly violent). Through the mother's back the child "sees" what is happening to the mother's rear and could even resemble what it sees. Among the Sawa (Duala) ${ }^{12}$ the pregnant woman will benefit from allowing to pass or sleep behind her any person noted for the delicacy of their features or the elegance of their gestures. Similarly, she will be well advised to avoid any person whose physical features or moral 
characteristics are considered undesirable.

The fetus sleeps and wakes at regular intervals by day and by night. It feeds, either by mouth or by the cord, on the food eaten by the mother, which is in the amniotic fluid. It is thought that at six months sexual relations are sufficient to nourish it. It may be satisfied or not by its mother's food. If it refuses this food the mother will feel nausea (frequently followed by vomiting) and suffer diarrhoea, cramp or flatulence. The fetus may want more food and the mother will then feel hungry. Finally, the fetus often feels the need to urinate. In that event the mother will suffer from pollakiuria (the need to urinate frequently).

This brief survey of beliefs and knowledge on the physiology of the genital organs and the biological mechanisms of conception reveals a richness of symbolism founded on the spiritual and natural (that is, the "properly physiological"). On these beliefs and knowledge will depend the social experience of pregnancy in its psychological, physical and behavioural dimensions.

\section{The Social Experience of Pregnancy}

A woman's realisation of her pregnancy is based on the classic "presumptive" signs such as the absence of periods; a frequent feeling of fatigue after periods cease; engorgement of the breasts (felt in the form of contractions); nausea, mainly in the morning; pain in the lower abdomen, etc. Once the pregnancy is identified or presumed its social experience will depend essentially on a preventive therapeutic programme consisting on the one hand of divinatory consultations whose object is to ensure the proper development of the pregnancy to determine the sex of the child and whether they are twins and on the other of alimentary and behavioural prohibitions and prescriptions.

\section{Divinatory Consultation, Purification and Exhortation}

The divinatory consultation occupies an important place in the process of childbearing. It is a technique of investigation used to probe and interrogate the invisible on the physiological state of the pregnant woman, and to identify the dangers and means of countering them. It is part of a logic of purification and prevention of threats and anomalies to which the woman may become subject during this process. Among the Banen, ${ }^{13}$ pregnancy is inaugurated with a rite known as "purification of the seed", either by a bath in pure water (drawn from a spring at dawn in a new vessel by a virgin) or by the sacrifice of a brace of birds. In addition the pregnant woman, particularly one who has an excess of blood (assimilated to polyglobulia), will undergo a rite known as discharge, the object of which is to prevent congenital malformations. Among the Yambassa $^{5}$ the object of the divinatory consultation with a soothsayer/healer (by means of the trap-door spider) is to determine the sex of the infant and whether it is twins as well as to ensure the good health of the fetus and mother and the normal development of he pregnancy. The divinatory consultation may lead to a therapeutic programme of drugs or ritual according to the revelations by the trap-door spider. Among the

This rite will be an opportunity for the pregnant woman to get rid of her excess blood (infusions of libations, scarifications 
Babouantou, ${ }^{9}$ as among the Wuli, ${ }^{11}$ the divinatory consultation is justified only by the occurrence of a health problem or a complication (for example, the threat of abortion) during the gestation and only for therapeutic purposes. It is also an occasion for forecasting the course of the delivery.

\section{Alimentary and Behavioural Probibitions and Prescriptions}

In order to ensure a fortunate term to the pregnancy and preserve the baby from any physical or congenital flaw (malformation or defect), the pregnant woman and her partner are required, separately and in their common life, to observe a number of alimentary and behavioural prohibitions and prescriptions. These become severer as the pregnancy progresses. Some of the prohibitions and prescriptions are of a general nature and fixed a priori, while others, more individualised, are imposed later as the result of divination by the soothsayer/healer. As in many other African societies, ${ }^{12}$ pregnancy in the ethnic groups of Cameroon passes through three major stages corresponding to the three trimesters, each of them with specific prohibitions and prescriptions.

The first stage corresponds to the first trimester of pregnancy (one to three lunar cycles with no periods). The woman believes that she is probably pregnant on the basis of the classic signs described above. At this stage it is believed that the product of conception is merely a mass of blood, a mollusc, which is not yet a true pregnancy. The woman has every interest in keeping the news secret, far from jealous and malevolent spirits ${ }^{1}$, and in order not to anticipate the divine will of the powers of the beyond (geniuses, ancestors) on a pregnancy that is still uncertain. This discretion in the early stages allows the woman to avoid the ridicule, which a false alarm of pregnancy could bring. She will speak of it only to close relatives in case of necessity. In certain ethnic groups such as the Yambassa, women may not even speak of it to their husband, because it is the husbands who betray the secret of their new physiological state in their conversations with other members of the group. The husband, of course, will notice the pregnancy for himself. This permanent concern for discretion may constitute an obstacle to the woman's use of antenatal services, particularly an early enough first consultation, which according to current norms ought to take place latest during the first trimester of pregnancy. It may be perceived as a potential occasion for breaking the secret and thus as a source of danger.

The second stage corresponds to the second trimester of pregnancy (three to six lunar cycles with no periods). During this period the woman gains the status of "pregnant woman". This is the time to observe the alimentary and behavioural prohibitions and prescriptions. ${ }^{14}$ Although she is now certain of her pregnancy, the woman will still pretend not to know this even though she can no longer deceive those around her, the older women (experienced multiparas) and traditional birth attendants who are able to detect the pregnancy in its early stages by physical signs. First they observe a change in the woman's features, with the occurrence of a pale complexion, the appearance (or the increase) of pimples on the face and a reddish down extending from the temples to the cheeks. ${ }^{5,9}$ This change is well known in medicine as chloasma or 
"pregnancy mask". When they bathe together in the river the "women who know" notice that the pregnant woman has a black line running from the navel to the pubis. In addition "the breasts have acquired a handsome chestnut colour, with the tips completely black and surrounded by aureoles of small spots instead of being uniform". ${ }^{5}$ The woman will frequently be the subject of jokes from her friends: "she is suffering from a good illness which is only a matter of time," say the Yambassa. ${ }^{5}$

Finally the third stage corresponds to the last trimester of the pregnancy (six to nine lunar cycles with no periods). This is a crucial stage when the prohibitions and prescriptions are even stricter in preparation for the delivery. The pregnancy has developed, the abdomen has grown in size and the woman is beginning to feel the fetus moving. It is no longer possible to conceal the fact of pregnancy. To any who enquires about the physiological state of his wife the husband will almost always reply by periphrases such as "I chased the animal and killed it".

\section{Alimentary Prohibitions and Prescriptions}

Alimentary prohibitions and prescriptions are among the precautions taken to ensure the birth of a healthy and normal child, that is, one free from any physiological, physical or psychological defect. Generally speaking, the pregnant woman must avoid any food that can give rise to a physical or psychic indisposition. Since the fetus feeds on whatever its mother eats, any malaise following the eating of a particular food is perceived as a refusal of that food by the child. The alimentary prohibitions and prescriptions are of such diversity that it is difficult to give an exhaustive list. As Table 1 shows, they concern all categories of food (meat and fish, fruits, vegetables and starchy foods, tobacco and alcohol), frequently depriving the woman of nutritional elements necessary for the proper development of her pregnancy.

Although some foods are proscribed, others are strongly recommended. These are generally foods that are symbols of fertility (or of fertilisation) or which have virtues facilitating delivery. Eating these foods amounts to repeating the act of fertilisation by the oral route in order to neutralise any move for the destruction of the fetus by negative forces. In order to ensure proper nourishment of her body and the intrauterine environment and avoid giving birth to an underweight baby, a pregnant Bassa woman ${ }^{6}$ will eat large quantities of beef (except the feet) and palm caterpillars (white worms), which are reputed to be particularly rich in proteins. In order to avoid anaemia and facilitate labour and the expulsion of the child a pregnant Yambassa woman $^{5}$ will eat a great quantity of gourd leaves, okra and cassava. She will seek to protect the skin of the fetus and strengthen its bones by eating kaolin (white clay). In order to overcome fatigue and ensure a sufficient supply of milk, a pregnant Bafia woman ${ }^{15}$ will eat vegetable soups.

In some cases the father is also subject to certain alimentary prohibitions and prescriptions. Among the Bassa ${ }^{6}$ he must preserve the purity of his blood by avoiding drunkenness and abstaining from eating viper and certain fishes; palm rat (which lives underground and is supposed to touch the dead); snails, at the risk of making the child to 
Table 1 Alimentary Prohibitions and Prescriptions according to Ethnic Groups in Cameroon

\begin{tabular}{|c|c|c|c|}
\hline Category & Description & Consequences in case of transgression & Ethnic groups \\
\hline \multirow[t]{19}{*}{ Meat and fish } & Birds & $\begin{array}{l}\text { 1. Prevents development of breasts in pregnant } \\
\text { women }\end{array}$ & Bassa, Beti \\
\hline & \multirow{2}{*}{$\begin{array}{l}\text { Fish (silurid, carp, } \\
\text { machoiron*) }\end{array}$} & 2. Haemorrhage and risk of abortion in woman & Bakoko, Bassa, Beti, \\
\hline & & $\begin{array}{l}\text { 3. Child would be born without physical } \\
\text { consistency, careless and indolent, with } \\
\text { bronchitis, epilepsy or dermatoses }\end{array}$ & Yambassa \\
\hline & Reptiles & 1. Child would be born with an elongated body & Bakoko, Beti \\
\hline & Antelope/wart-hog & $\begin{array}{l}\text { 2. Haemorrhage and risk of abortion in woman; } \\
\text { child would be born with a chronic state of } \\
\text { somnolence, with convulsions or dermatoses } \\
\text { (of leprosy) }\end{array}$ & Banen, Bassa, Beti \\
\hline & Wild rat/crow & $\begin{array}{l}\text { 3. Risk of abundant haemorrhage during } \\
\text { delivery }\end{array}$ & $\begin{array}{l}\text { Bafia, Bassa, Beti, } \\
\text { Yambassa }\end{array}$ \\
\hline & & 4. Risk of infant's death from chronic diarrhoea & \\
\hline & Porcupine & 1. Causes or aggravates oedemas in woman & Maka \\
\hline & Snails & $\begin{array}{l}\text { 2. child would slaver all its life or would be born } \\
\text { with hepatitis }\end{array}$ & Bassa, Beti \\
\hline & Dog-faced baboon & $\begin{array}{l}\text { 3. Child would be born with chronic whooping } \\
\text { cough }\end{array}$ & Beti \\
\hline & Elephant/buffalo & $\begin{array}{l}\text { 4. Child would be born with a large head, coarse } \\
\text { skin or fan-shaped ears }\end{array}$ & Bassa, Beti \\
\hline & Monkey & 5. Child would be born with convulsions & Beti, Yambassa \\
\hline & Pangolin/weaver-bird & $\begin{array}{l}\text { 6. Risk of chronic impotence or being born with } \\
\text { epilepsy }\end{array}$ & Bassa, Beti \\
\hline & Guinea fowl & 7. Risk of retention of child or placenta at delivery & Foulbés \\
\hline & Pig & 8. Child would be born too big & Bafia, Bassa \\
\hline & Chimpanzee/gorilla & 9. Child would have their face and their walk & Bassa \\
\hline & Leopard/lion & 10. Risk of child being a murderer & Bassa \\
\hline & Duck or bat & 11. Child would be born with chronic rickets & Bafia, Beti \\
\hline & Egg & 12. Child would be born without hair & Beti, Yambassa \\
\hline \multirow[t]{8}{*}{$\begin{array}{l}\text { Vegetables and } \\
\text { fruits }\end{array}$} & Pineapple/banana & $\begin{array}{l}\text { 13.Child would be born covered with scabs, sores, } \\
\text { scratches or oedemas }\end{array}$ & Beti, Bassa \\
\hline & Taro & $\begin{array}{l}\text { 14. Child would be born covered with dirt; prevents } \\
\text { closing of fontanelle }\end{array}$ & Beti \\
\hline & Kolanuts & 15. Child would be born with hare lip & Yambassa \\
\hline & Beans & 16.Problems with spleen in child & Banen \\
\hline & Yams & 17.Leads to stammering in child & Beti \\
\hline & Macabo (red) & 18. Risk for child of diarrhoea and itches in throat & Bassa, Yambassa \\
\hline & Sugarcane & $\begin{array}{l}\text { 19. Reduces quality of mother's milk by excessive } \\
\text { dilution }\end{array}$ & Bassa, Yambassa \\
\hline & Cassava leaf & $\begin{array}{l}\text { 20. Reduces quality of mother's milk by excessive } \\
\text { dilution }\end{array}$ & Bassa \\
\hline Alcohol & Palm wine/beer & 21.Child would be born under-size and weakly & Yambassa, Duala \\
\hline Tobacco & & 22. Child would be born under-size and weakly & Yambassa \\
\hline
\end{tabular}

* The machoiron is a fish with sharp spines 
be born slaver; antelope (which would make the child tremble); tortoise (for then the child would suffer from diarrhoea); or monkey (the child would be born without fingers).

\section{Tobacco and Alcohol}

Generally speaking, the consumption of tobacco and alcohol by women is regarded negatively. It is seen as a sign of bad education, social debauchery or negative emancipation. A girl does well to avoid smoking or drinking at the risk of being rejected and ill-thought of by men. Only menopausal women can venture to do so. Smoking and drinking are, in principle, banned for pregnant women; the child would be born small and lacking in vigour and would develop into a smoker and alcoholic. In some cases the daily consumption of a moderate quantity of alcohol after birth palm wine among the Yambassa, beer among the Duala promotes the supply of milk.

\section{Behavioural Probibitions and Prescriptions}

During gestation the woman is required to redouble her vigilance in the matter of social morality. Thus, she will avoid any conflicts with those around her, touching other people's property, offending a child, or harming a domestic animal at the risk of having a miscarriage or a difficult delivery. ${ }^{1,12}$

\section{Gestures and Conduct to be Avoided or Observed}

Dead body, or anything connected with it, is to be avoided as much as possible, for that can be baneful for the child to be born. A pregnant woman will take care not to go near a grave, enter the house of a dead or dying person or take part in a ritual associated with death (for example a funeral). Among the Mouyeng of the North $^{16}$ a pregnant woman will avoid speaking of or referring to a miscarriage, a death in utero or a difficult delivery; lest that should have an evil influence on the progress of the pregnancy and the course of the delivery.

For the risk of having the child reluctant to emerge during delivery, a pregnant Beti woman ${ }^{4}$ will not speak from the threshold of a house, but only when she has passed through it into the interior. For the same reason a Bassa woman ${ }^{6}$ will never remain on the threshold or lean out of a window. To ensure a good presentation for the fetus the Bassa woman ${ }^{6}$ will never cross her legs when she is sitting down, or carry a hoe round her neck, or plait other women's hair. For the risk of having a difficult labour or restricting the passage for expulsion of the fetus, she will not close the door with both hands, will never embrace strangers (breast against breast), and will not touch the morning dew or spiders' webs obstructing the passage. She will avoid splitting wood for the risk of having her child born with a big head and wide fontanel. So that her child may have a happy face she will avoid any attitude suggesting sadness. To ensure that her child will have fine eyes and a pleasant look, a pregnant Beti ${ }^{4,17}$ or Bassa woman ${ }^{6}$ will never look with one eye into a bottle or the hollow of a tree, will not drink from a gourd while raising her head (the child would have a squint) and will not touch incense (the child would be born with pus on its eyes). A Beti woman $^{4}$ will avoid approaching a chameleon lest her child suffer from a state of chronic emaciation.

For the hygiene of the fetus, a pregnant Bakoko woman ${ }^{8}$ will take a purge every two to 
four days. A Babouantou woman ${ }^{9}$ will avoid taking off the fire or putting on to it a pot with a lid. She will take care to remove the lid for the risk of giving birth to a dumb child. To preserve her child from any character of violence, a pregnant Bassa woman ${ }^{6}$ will wear a palm leaf fibre round her neck and her loins. She will always look at something beautiful and will be careful about whom she eats with, for this will make sure that her child will be wise, good natured and of pleasant manners. A pregnant Beti woman ${ }^{1}$ will make herself a piece of "armour" to protect her pregnancy against evil influences, getting her mother or other trusted person to make her a "bellyband" of rattan fibres (three knots to the left and three to the right), worn as low as possible so as to avoid restricting the growth of the fetus, which she will take off only at the time of delivery. To avoid an abortion, a pregnant Bassa woman ${ }^{7}$ will wear round her loins, from the first weeks of her pregnancy, a rope made from some vegetable fibre (for example, rattan), which is difficult to cut with hand, with nine knots. She will keep this on until the ninth month of pregnancy.

\section{Physical Activity during Pregnancy}

Physical activity usually continues during gestation, though as a rule a pregnant woman gets help from members of the family (her husband, mother-in-law, children, etc). A pregnant Bakoko woman ${ }^{8}$ carries on her usual occupations until the end of her pregnancy, which sometimes leads to premature delivery in the plantations or while fishing. A Banen woman ${ }^{18}$ will continue working as long as her pains permit. Physical labour is sometimes prescribed with the idea of making the fetus move and as a method of relaxation for labour. Among the Bassa ${ }^{6}$ a pregnant woman will avoid violent and arduous physical work until the 6 th or 7 th month of gestation. From the 7th or 8th month, however, this type of work is particularly recommended for her in order to give her the drive, courage and endurance required for the ordeal of delivery. Nevertheless, while doing this work, she will be careful to rest from time to time and will avoid working in a steady and continuous fashion. Periods of relaxation of the muscles (stretching of the limbs and body) are strongly recommended.

At the opposite extreme, a pregnant Beti woman ${ }^{4}$ is progressively relieved of her usual occupations as her pregnancy follows its course. She receives a great deal of help from her family.

\section{Sexual Activity during Gestation}

In many ethnic groups sexual relations between the partners continue until an advanced stage of the pregnancy, that is, until the child is judged to be completely formed and viable. This is a prescription that is based almost entirely on the nutritive value of the seminal liquid for the fetus. Among the Bassa, ${ }^{6}$ if the father falls ill or is obliged to go away before the child is completely formed in the womb, his contribution is replaced by a therapeutic programme of drugs consisting of (i) a food based on gelatinous plants like ndjango, okra and wild mangoes; and (ii) enemas made from mucilaginous plants alternating every two days, for example, once with leaves of hibiscus and the pollen of flowers, another time with leaves of nvagmikob 
(sticky edible leaves). Among the Yambassa, for example, it is believed that the fetus can develop only as a result of the sexual relations, which the parents will continue to maintain during pregnancy. In their view a pregnant woman benefits from not being deprived of "man's blood" (sperm); otherwise she might give birth to a puny and sickly infant. This belief is also found among the Beti, ${ }^{1,4,17}$ where it is thought that sperm contributes to the better physical fashioning of the child. Among the Babouantou, ${ }^{9}$ in addition to its nutritive and fortifying virtue for the fetus, sperm is recognised as having a therapeutic mechanical property for delivery. It is believed to promote the mechanical enlargement of the passage for the expulsion of the fetus. A woman who deprives herself of it or suspends sexual relations with her husband prematurely runs the risk of a difficult labour and delivery, since her genital organs would have lost the habit of being dilated mechanically. Nevertheless sexual relations are not generally recommended right up to the end of the pregnancy. As a rule they begin, for various reasons, to die down between two and three months before the birth. Among the Beti $^{4}$ the suspension of sexual relations shortly before the birth is justified on hygienic and sanitary grounds. It is necessary to avoid incommoding the traditional birth attendants by the deposits of sperm on the infant's body created by the non-observance of this prescription. In addition by finding its way into the mouth of the fetus the male seminal liquid might give the infant a cold in the head. The Delivery
When a pregnant woman has nine or ten notches on the stick that she uses to mark and count her "moons" her partner and she will prepare themselves for the fateful event of the delivery. After she has succeeded in protecting her pregnancy against evil spirits, her delivery is the final crucial stage, which is awaited with a mixture of hope and anguish. The final divinatory consultations with a soothsayer are carried out with the object of forecasting the result of the delivery and prescribing appropriate directives. The woman will eat by preference sticky foods, will have frequent enemas based on gelatinous liquid, will engage in physical efforts in order to promote the dilatation of the uterine passage and will relax her muscles in preparation for the pains of giving birth.

\section{Place of Delivery: A Congenial Atmosphere Preserving the Mother's Intimacy}

The place of delivery is selected to meet the permanent concern for discretion, security (for example, the fear of malevolent sorcerers) and a congenial atmosphere. The parturient's original family is very frequently the most suitable place. When this is the choice, the maternal family, with the parturient's mother providing care, takes a solemn commitment to ensure the safety of the delivery. Among the Bassa $^{7}$ there is an old adage: Mut a top be iyana sop (meaning "No one has the right to make a hole in anyone else's gourd. A mother must make a hole in her own gourd"); that is, a mother must make herself responsible for the safety of her daughter and must accept the risk of something going wrong. For, as among the Beti $^{4}$, the mother is the person who can best 
look after her daughter without repugnance. Delivery in the paternal family, though not totally excluded, is a second best. As much as possible the father's family will be avoided, since they may have reasons for resenting the new infant (jealousy, competition between children for the family inheritance, etc). In the mother's family of origin on the other hand, the safety of mother and child is guaranteed and will be the object of attentive and delicate care.

In general the delivery takes place in a discreet place, far from envious and jealous glances that might cause or prolong the mother's sufferings. A delivery in public is almost always perceived as a calamity. Among the Beti ${ }^{1}$ it is thought that an enemy might collect the parturient's blood in order to bring about the death of the newborn and prevent all future births. It is for this fundamental reason that a woman will choose as much as possible to give birth where she will feel safest (in her native village, in her mother's or a sister's house).

The delivery takes place in the kitchen, behind the family hut, on the delivery stone, on the ground, on a mat, on leaves or under a banana stem, or on a bamboo bed made for the purpose. The space is prepared for a single parturient, for it is out of the question for several women to give birth together. It frequently happens, as the result of some imprudence or poor preparation for the birth, that a pregnant woman is overtaken by labour or delivery far from home in the fields, at the marketplace or while travelling. When labour begins and the pains become increasingly pressing a Yambassa woman ${ }^{5}$ tries to retain the child in her womb until she gets to the family home. She will pick up a pebble and hold it in her teeth when she feels a labour pain. This is an essentially psychological therapeutic measure. When, in spite of everything, a birth far from home cannot be avoided the woman is left to her own resources and will be ready to accept any suitable help, even from a man.

Assistance in Childbirth: In the First Place a Matter forWomen

Childbirth is in the first place a matter for women, an exaltation of femininity; and men, including the father of the child, must keep away from the place of delivery. Among the Ewondo (Beti tribe) ${ }^{19}$ and the Fufuldé, men are called on in the event of a mechanical dystocia, their role being mainly to shake the parturient vigorously in order to accelerate the descent of the fetus. In other ethnic groups, like the Wuli ${ }^{11}$ and the Kirdi, ${ }^{20}$ the function of birth attendant (which is generally hereditary) may fall to a man as well as a woman. Among the Wuli, ${ }^{11}$ the male holder of this post will choose his successor from among his children, nieces or nephews. He inherits the ritual post and the secret of the plants accompanying the ritual, but whichever of his wives was born outside the norms will be his assistant, will inherit the necessary know-how and the secret of the plants associated with it. In most of the ethnic groups of North Cameroon the traditional birth attendant is preferably female, a man being tolerated only if he belongs to the family, and particularly when a mechanical dystocia is involved. Among the Fali, ${ }^{22}$ only the woman's partner or his brothers may be present at the birth but may not intervene directly.

Gestures and Procedures Relative to the Delivery: Flexibility and Congeniality 
The first shooting pains in the loins and lower abdomen mark the beginning of labour. Among the Bassa ${ }^{7}$ these pains give the feeling of "a fire close to the pelvis which gives rise to a heat that in the long run is unbearable". A Yambassa woman ${ }^{5}$ performs her toilet and prepares the place where the birth will take place. The matrone is then told: "Even if you are going somewhere today, do not go far, and above all come back quickly."

During labour the woman is given liquids to drink in order to facilitate delivery especially if it is difficult. Among the Mada and the Mouyeng ${ }^{16}$ it is a libation of millet diluted in a little water. In many other ethnic groups, like the Yambassa ${ }^{5}$ and the Ewondo, ${ }^{19}$ it is a maceration of herbs with oxytocic properties that produce uterine contractions. Among the Banen ${ }^{13}$ a little ash diluted in a glass of water is enough to accelerate the delivery. The woman gives birth in a semiseated or crouching position, on her knees with her upper body leaning forward, supported on her hands, or lying down on the delivery stone on the ground or on banana leaves (a symbol of fertility). The matrone turns the fetus towards the exit in the normal position (that is, head first) by massaging the parturient's abdomen. Meanwhile prayers are said, the spirits are invoked so that all may go well, and above all there are oral incantations of psychological value, the therapeutic (or instrumental) efficacy of which resides, in our view, in the belief of those concerned in their power of giving freedom from pain, painless childbirth being one of the principal virtues sought.

The breaking of the waters occurs automatically under the effect of the uterine contractions or is brought about mechanically by the matrone after vaginal palpation. Among the Fali $^{22}$ this liquid has fertilising virtues and beneficial qualities for health; accordingly the women present at the birth rub themselves with it. Delivery is then achieved with the emergence of the newborn, usually by the head, and the placenta, under the influence of the uterine contractions. The spontaneous cries of the infant signs of life and vitality can then be heard. When necessary, the Babouantou matrone ${ }^{9}$ will clear the child's respiratory passages of any obstructions by sucking its nose and mouth. If this fails, as a last resort, the matrone chews a pepper and inserts it into the child's nostrils; a method of re-animation considered very efficacious, which automatically stimulates the child's cries. If this fails it is a clear sign of a stillbirth.

After delivery the umbilical cord is cut using a variety of materials such as a splint of raffia, razor blade, a sliver of bamboo, sharpened millet stalk coated with red kaolin mixed with cailcedrat oil, a sherd of pottery, an oyster shell, a special knife used for circumcision and infants' navels. The cord is cut either directly or after being ligatured (with braiding cord or nylon) at a variable distance from the navel; one centimetre among the Fali, ${ }^{22}$ two centimetres among the Yambassa, ten centimetres among the Bakoko ${ }^{8}$ and the Beti, ${ }^{4}$ and five to thirteen centimetres among the Babouantou'. The ligature and umbilical dressing are usually made from a piece of the parturient's loin cloth or a string with a variety of substances such as clay, powdered pottery, palm oil, ashes, shea butter, etc. The navel does not get

$A$ birth is outside the norms when it is afflicted with severe congenital malformations 
any dressing in the proper sense; it is usually given a coating of a mixture of substances that causes the cord to drop off after three to seven days. Dugast ${ }^{18}$ had a biological analysis made of the coating used among the Banen, which gave the following result: water $6.43 \%$, ashes $28.10 \%$, ethereal extract $20 \%$, phenols $40 \%$ of the ethereal extract or $8 \%$ of the soot. According to the analyst, the phenols are certainly responsible for the antiseptic action of this soot. Carbon has an absorbent and anti-coagulant power. This is the reason for its use in Africa for the cicatrisation of the navel in newborn infants.

Sterilisation of material used for the ligature and the umbilical dressing is done with hot water and/or soap; but alcohol or perfume is now increasingly being used. The placenta, the umbilical cord and the maternal breast are physiologically and intimately connected. Accordingly the placenta and uterine blood will be preserved from all evil influences, hidden or buried in some discreet and secret place so that no spells may be wrought on the mother or the newborn through them. Among the Bangoua ${ }^{10}$ and the Bakoko ${ }^{8}$ the placenta is carefully wrapped up in leaves and buried deep underground within the village under a banana tree (a symbol of fertility) whose fruit is in the process of ripening (the mother cannot eat it). By this means the infant is linked with its father's land and symbolically inscribed in his filiations.

The birth of the baby is an occasion for manifestations of joy, which is more intense if it is a boy. After delivery the mother is given ritual massages and her abdomen and genital organs are washed with very hot water. She also receives infusions and soup. The object of these essential therapies is to promote the reestablishment of her strength and organs by getting rid of the clots of coagulated blood remaining within her abdomen, which are believed to cause pain and flatulence. Among the Yambassa ${ }^{5}$ it is thought that this coagulated blood can cause sterility in the woman. Among the Bakoko ${ }^{8}$ the mother will also have hot purges of boiled water with leaves of the bush butter tree in order to clean and restore the intestinal passage. The rites of purification and protection complement the care given to the mother in order to give her every prospect of future births.

\section{The Biomedical Logics of Obstetrical Services and Care in Cameroon}

The Follow-Up of Pregnancy

The programme for the follow-up of pregnancy (antenatal consultations) in Cameroon is fundamentally based on the risk approach. The monitoring of a pregnancy is considered sufficient if the pregnant woman:

(i) is cared for (with antenatal consultations) by a qualified health professional (doctor, midwife or nurse);

(ii) has her first antenatal consultation in the first trimester of her pregnancy;

(iii) has at least four antenatal consultations: the first in the first trimester, the second about the sixth month, the third in the course of the eighth month and the fourth in the ninth month;

(iv) has at least two anti-tetanus injections. However, if she has already had an injection during a previous pregnancy one dose will suffice for the later 
pregnancy. This vaccination wards off neonatal tetanus, one of the causes of neonatal mortality.

Assuming that these recommendations are scientifically valid, their efficacy in terms of health benefit depends on the ability of the health services to cover the whole population. But this coverage in turn depends on the cultural acceptability and geographical and financial accessibility of the obstetric services. These requirements seem to be still far from being satisfied in Cameroon. The offer of antenatal care is still based on an approach whose technical efficacy is doubtful; the quality of the relationship between health personnel and the population is far from being satisfactory and, so far, takes no account of the demand; and the organisation of the system is insufficient to permit the evacuation in time and at an accessible cost of women who require an obstetric intervention in health services.

Ultimately in Cameroon antenatal consultations have not yet been rationalised and the availability of care is most frequently reduced to a ritual for the detection of risks. Moreover, the quality of relationship between health personnel and the population has not yet reached an acceptable standard. In addition, the peripheral level (the health centre) and the first referral level (the maternity department of the hospital) are cruelly short of qualified staff (midwives, doctors) capable of performing emergency obstetric interventions. Finally the system of referral and evacuation is subject to considerable constraints of accessibility both geographical (poor condition of roads, scarcity of means of transport) and financial. ${ }^{23}$

Thus, the availability of modern antenatal services in Cameroon is both technically poor and little in touch with the women they serve.

\section{The Delivery Care Facilities}

In spite of the current context of economic austerity, the availability of health infrastructures offering obstetric care is increasing. Ministry of Health statistics show that the number of health infrastructures increased from 847 in $1974 / 75$ to 1,819 in 1992/93, though with considerable disparities to the detriment of the Far North and the North-West/South-West. ${ }^{23}$ This quantitative improvement is partly due to the involvement of non-governmental organisations and private non-profit organisations, particularly in rural areas, where the majority of the poor live. The geographical accessibility of services, however, is still deficient, mainly because of the long distances to be covered, the isolation of particular regions and the shortage of means of transport. More than $45 \%$ of women live more than $5 \mathrm{~km}$ from the nearest obstetric service and have no access to motorised transport for getting there. In addition to this poor accessibility of services the conditions in which care is given are not always satisfactory. ${ }^{23}$

The maternity hospital is generally

That is not the case. Because in recent years the ability of the antenatal services to reduce effectively the levels of mortality and morbidity has been again (as it had been in the 1930s) ${ }^{45-36}$ brought into question more particularly where its efficacy was essentially linked with the detection of risks in pregnant women. The present consensus is that even in a developing country in which the prevalence of risks is highest the detection of risks haspoorpredictive value, mainly because of its low sensitivity (30\%) and relatively low specificity (around $90 \%)^{3 .}$ 
divided into a series of departments corresponding to each of its specialised interventions. From the reception desk, where the consultation fees are paid, the pregnant or parturient woman passes necessarily frequently facing long queues, through a multitude of work stations like the registration department, waiting room, examination room, operating suite or delivery ward, recovery room, day room or mortuary (in a fatal case). The patient (as she is called in Cameroon), according to her condition, must submit herself to the medical routine and the standard treatments; seated or recumbent position, body adjusted to medical equipment and instruments, ban on eating and drinking, weighing, a battery of examinations (urinary, haematological and radiographic), induction of labour, monitoring, etc. They emerge from all this, usually relieved, with medical and behavioural prescriptions where required, the date and place of their next appointment and, for those who can afford ultrasonography, a more or less clear idea of their physiological state, sex of the child and whether it is twins.

The length of stay in hospital depends, in principle, on the gravity of the case, but it seems frequently to be determined by reasons that are not always explained to the woman. Visits by her family and the bringing of various foodstuffs are prohibited or, at best, tolerated. Moreover, the circumstances of the hospital can generate stresses and frustrations over which the woman has little control. Such circumstances include the constant violation of her intimacy and her living space by the presence of other mothers, the multiplicity of caring personnel, sometimes involving ambiguous or contradictory information, and the check on the baby's layette. And when the layette is insufficient there may be mockery and criticism. The economic crisis, which has accompanied the crisis in the health system, has created or aggravated malfunctioning such as the bringing by patients of their own medical (alcohol, fingerstalls, cotton, dressings, etc) and other requirements (e.g., a mattress), the poor arrangements for the reception of patients, corruption in the provision of care, the fraudulent diversion of patients to private health care centres, etc. Various situational studies since the early 1980s have revealed clear examples of such malfunctioning. ${ }^{24-28}$

In spite of the malfunctioning of the Cameroonian health system, access to obstetrical services and care is better for the maternal and child health. Neonatal mortality rate (probability of dying in the first month of life) is closely related to antenatal care and medical assistance at birth. The neonatal mortality rate is highest in the absence of antenatal care from trained health personnel and medical assistance at birth and lowest in the presence of maternal care (Table 2).

Table 2 Neonatal Mortality Rate (per 1000 live births) by Medical Maternity Care in Cameroon

\begin{tabular}{lcc}
\hline & DHS 1991 & DHS 1998 \\
\hline No antenatal/delivery care & 57.1 & 47.3 \\
\hline Either antenatal/delivery care & 37.7 & 25.2 \\
\hline Both antenatal/delivery care & 23.1 & 27.5 \\
\hline
\end{tabular}

Source: Cameroon DHS reports (1991 \& 1998). 


\section{Evidence from the Qualitative Survey}

The results presented here are based on an analysis of the content of the discussions, bringing out the general tendencies.

\section{Expectations Expressed}

From the group discussions there emerges a definition of ideal arrangements for caring for pregnancy and delivery, around which are expressed a variety of expectations. These arrangements not only guarantee a favourable outcome but also are carried out in accordance with traditional customs and in conditions that are culturally, geographically and economically acceptable. Thus, it appears that the women unsurprisingly want:

adequate care for obstetric infections and complications;

care which is easily accessible at the lowest possible cost;

respect for discretion in consultations; preservation of their intimacy; and that the minimum package of care should include traditional forms of care of whose efficacy they are sure (e.g., massages).

\section{In addition, they want:}

to know the sex of the child in the womb and whether it is twins;

to have complete responsibility for the use made of the products of birth (placenta, umbilical cord) after delivery; the comforting presence of their family throughout the process of giving birth; the possibility of painless childbirth; and more humanity and responsibility in the behaviour of the providers of care.

Facilitating and Off-Putting Aspects of the Two Systems of Obstetric Care

In relation to the expectations expressed, we asked members of the discussion groups to enumerate the advantages and disadvantages of giving birth in hospital or in accordance with tradition. The results (Table 2) reveal tensional elements as well as points of convergence.

\section{Advantages of each system}

The therapeutic efficacy of the biomedical system was not questioned. As regards the care of pregnancy there was particular appreciation of its ability to determine the sex of the child and whether it was twins, to detect efficiently at-risk pregnancies and to care for malaria, and the prevention of neonatal tetanus by vaccination. As regards the management of labour, there was appreciation of the control of pain, caesarean births and the handling of stillbirths.

Positive aspects of the traditional system of care were seen as its economic and geographical accessibility, its concern for preserving the woman's intimacy, its ability to provide better treatment of anaemia and women's "worms", the scope it offers for traditional customs of protection and purification, the massages after delivery, its concern for a comforting family presence and the non-insistence on the infant's layette. 
Table 3 Comparative Advantages and Disadvantages of the Biomedical and Traditional Systems for the Care of Pregnancy and Childbirth (Group Discussions in North Cameroon)

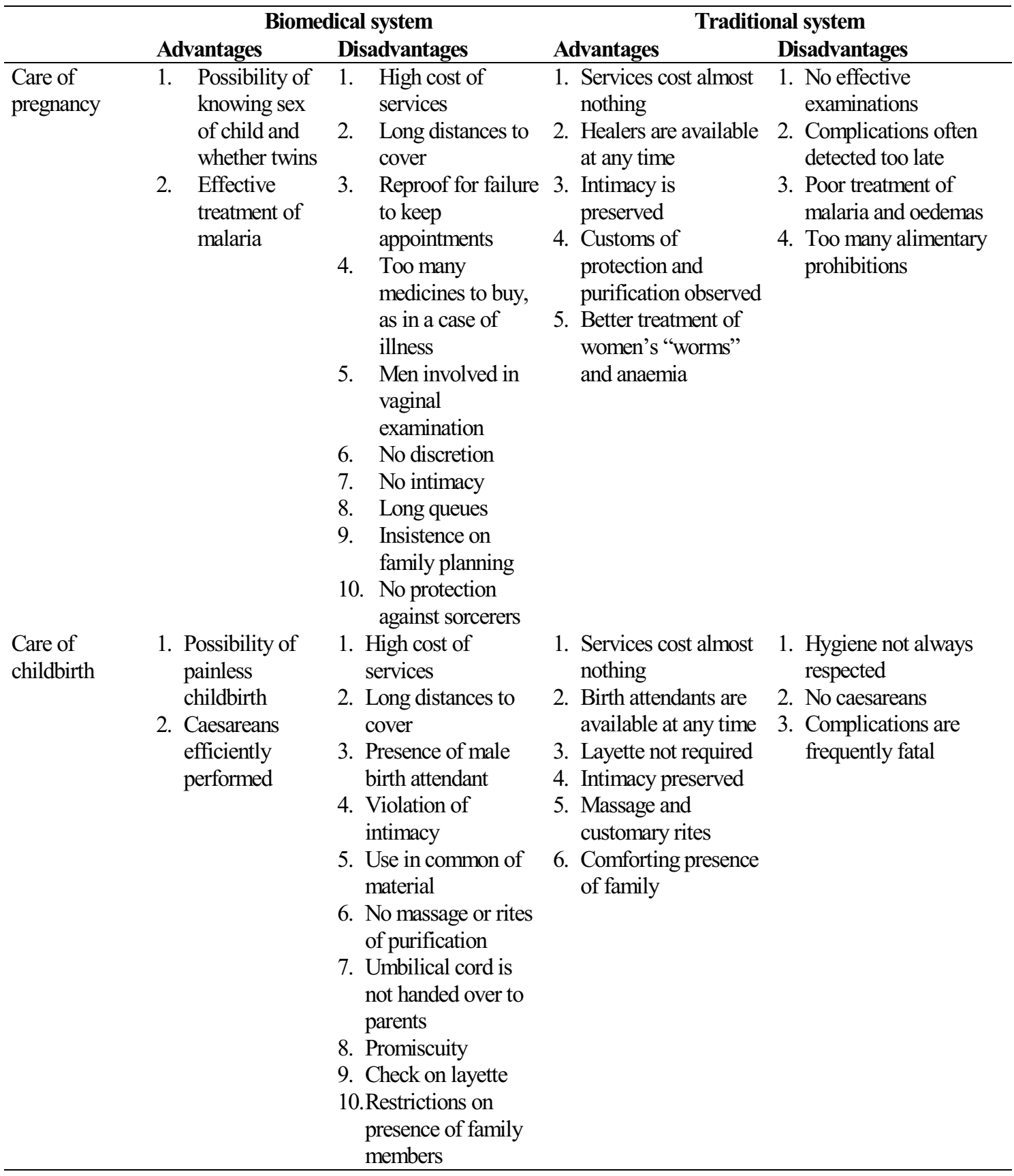




\section{Disadvantages}

In parallel with the advantages that are highly appreciated in the two systems certain deficiencies are also deplored. The disadvantages of the biomedical system are as follows:

1. Economic and geographical inaccessibility of its care and services.

2. Constant violation of women's intimacy by the presence of male birth attendants.

3. Use in common of material of obstetric interventions.

4. Failure to maintain the timetable of consultations.

5. Shortages of layette.

6. Absence of massages with hot water macerated with plants and bark (intended to restore the woman's strength and drive out of her body the "soiled" blood which puts her life in danger).

7. Failure to return to the parents the placenta and umbilical cord.

8. Lack of information and communication from health personnel.

9. Long queues.

10. Promiscuity in the hospital wards.

11. Enthusiastic promotion of family planning.

12. Restrictions on the presence of members of the family.

13. Inability to protect the mother and child from malevolent forces.

The deficiencies of traditional medicine are its inability to detect at an early stage and provide care for complications (fetal death, caesareans, malaria, oedema), the numerous alimentary prohibitions and the failure to maintain strict hygiene.

\section{Discussion and Conclusion: The Challenge of Complementary}

The obstetric context of Cameroon brings together at least two health systems (biomedical and traditional), each having its constructed interpretative models of normality and pathology and its preventive, diagnostic and therapeutic methods related to its basic ideological approach; a holistic approach for the traditional system, singular (centred on the individual or the patient), rational and biological approaches for the biomedical system.

The empirical example of North Cameroon supports the hypothesis of an inadequate match between the availability of biomedical obstetric care and the expectations of the population. The technical content of modern antenatal care is in need of being brought up-to-date, but the overall efficacy of the modern medical system is not questioned. The main challenge will be to improve its cultural acceptability by adapting the services available to the expectations of the population. The group discussions have shown that the cultural acceptability of the biomedical obstetric services and care on offer is prejudiced by the following features:

The earliness of the first antenatal consultation, fixed on a standard basis in the first trimester of pregnancy (in a way incompatible with the concern for discretion).

The presence of men among the caring personnel.

The use in common of delivery rooms and day rooms. 
The use in common of equipment required for obstetric interventions.

The absence of traditional forms of care like massage after delivery.

The refusal of health personnel to hand over the placenta and cord after delivery.

The refusal or limitation of the presence of family members during delivery.

The support of the population would thus be secured by a combination of the therapeutic efficacy of the biomedical system and the social efficacy of the traditional system. Therapeutic efficacy presupposes that interventions of proved efficacy within the budgetary limits are defined and promoted. Social efficacy presupposes that the compartmentalisation of medical disciplines is abandoned and the participation of the population is integrated into the definition and operation of health services. The important thing would be to make a transition from a normative medical service to an efficient and flexible medical system related to the expectations of the population, established with their participation (most of these expectations are not incompatible with biomedical therapeutic efficacy). This approach is known as patient-centred care. ${ }^{29-30}$

Let us not lose sight of the desired improvement of the geographical accessibility of health services, which is prejudiced less by the scarcity of health services than by the scarcity of the means of transport necessary to reach them (isolation of certain regions). All this calls for profound reforms, which go far beyond such vertical actions as the training of traditional birth attendants in practices. ${ }^{31-32}$ The results show if this was still necessary the importance of giving particular emphasis to the cultural acceptability of care as part of a patient-centred care approach in the training of health personnel.

\section{REFERENCES}

1. Laburthe-Tolra P. Initiations et sociétés secrètes au Cameroun. Essai sur la religion Beti. Karthala, 1985,437p.

2. Tessamann G. Die Pangwe, Völkerkundliche, Monograph, eines westafrikanischen Negretammes, Ergebnisse der Lübecker Pangwe 1907-1909 und Früherer Forschungen 19041907; Ernst Wasmuth, Berlin; Erster Band 275 pp.. in- $8^{\circ}$; Zweiter Band, in-8, 1913, 402 p (translated by Boumard).

3. Beninguisse G. Contextes médico-sociaux et prise en charge de la grossesse et de l'accouchement au Nord et au Sud Cameroun: une approche comparative. In: UEPA \& NPU (Eds).. La population africaine au 21e siècle, $2002 ; 5: 273-328$.

4. Ombolo JP. Sexe et société en Afrique Noire. L'anthropologie sexuelle Beti: Essai analytique, critique et comparatif. L'Harmattan, 1990,395p.

5. Onana Badang. Les jumeaux chez les Yambassa. Rites et croyances relatifs au phénomène gémellaire chez les Begunu. Mémoire de DES, 1979, 174p.

6. Daniel MA. Coutumes et croyances au sujet de la grossesse et de l'accouchement, mémoire de fin d'études, Editions de l'Agel, Lyon, France, 1972, $133 \mathrm{p}$.

7. Mbock II. Procréation et médecine en Afrique Noire. Mémoire de DES, 1978, 125p.

8. Buhan C and Kangue Essiben E. La mystique du corps. les Yabyan et les Yapeke de Dibombari au SudCameroun, Connaissance des hommes. L'Harmattan, 1986, 503p.

9. Nzikam Djomo. Les rites relatifs à la naissance. Mémoire de DES, 1977, 154p.

10. Charles-Henry \& Pradelles de Latour. 
174 African Journal of Reproductive Health Ethnopsychanalyse en pays Bamiléké, Epel, 1991, 250p.

11. Baeke V. La sage-femme et les femmes manquant de sagesse. Civilisations 1986;36(12):219-227.

12. Ewombé-Moundo E. La callipédie ou l'art d'avoir de beaux enfants en Afrique Noire. In: Lallemand S et al. Grossesse et petite enfance en Afrique Noire et à Madagascar, L'Harmattan, 1991, 41-19.

13. Mahend Betind. Rites et croyances relatifs à l'enfance. Présence Africaine, 1966, 146p.

14. Abega SC. Contes d'initiation sexuelle. Editions CLE, 1996, 228p.

15. Ngijoe MJ. Les pratiques traditionnelles qui influencent la santé reproductive de la femme dans la province du centre, Cameroun. Recherche réalisée dans le cadre du diplôme de technicien supérieur en soins infirmiers, Université de Yaoundé I, 1993, 146p.

16. Richard M. Traditions et Coutumes matrimoniales chez les Mada et les Mouyeng (Nord-Cameroun). Collectanea Instituti Anthropos, 10, 1977,359p.

17. Tsala-tsala JP. Ethnopsychologie des interdits pendant la grossesse. Cabiers Sociol Econom Cult Ethnopsychol 1996; 25: 86-88.

18. Dugast I. Monographie de la tribu des Ndiki, travaux et mémoires de l'institut d'Ethnologie 13(1), Université de Paris, 1960, 428p.

19. Cousteix PJ. L'art de la pharmacopée des guérisseurs. 1961,51p.

20. Fontaine M. Santé et culture en Afrique noire. Une expérience du Nord-Cameroun. L'Harmattan, Paris, 1995,319p.

21. Gauthier JG. Les Fali de Ngoutchoumi, vie Matérielle et Sociale et Eléments Culturels. Mosterhaut:
Anthropological Publications, 1969, 272p.

22. Beninguisse G. Entre tradition et modernité. Fondements sociaux et démographiques de la prise en charge de la grossesse et de l'accouchement au Cameroun. Thèse de doctorat, Institut de Démographie/UCL, Louvain-La-Neuve, Belgium, 2001,313p.

23. Van Der Geest S. The efficiency of inefficiency medicine distribution in south Cameroon. Soc $S_{c i}$ Med 1982; 16(24):214-553.

24. Hours B. Etat sorcier. Santé Publique et Société an Cameroun, L'Harmattan, Paris, France, 1985, $165 \mathrm{p}$.

25. De Maret $\mathrm{P}$ and Tonglet $\mathrm{R}$ (Eds.). L'Organisation du Système de Santé dans les Villes d'Afrique subSaharienne: Modèles et Pratiques, 1999 (in press).

26. Betbout H, Ngueyap F, Mudubu $\mathrm{KL}$ and Rakotondrabe P. Santé de la reproduction au Cameroun: situation dans les formations sanitaires. Les cahiers de l'IFORD, 23, 1998, 139p.

27. Israr SM, Razum O, Ndiforchu $\mathrm{V}$ and Martiny P. Coping strategies of health personnel during economic crisis: a case study from Cameroon. Trop Med \& Inter Health 2000; 5(4): 288-292.

28. Stewart M. Toward a global definition of patient centred care. The patient should be the judge of patient centred care. BrMed J2001;322: 444-445.

29. Mead N and Bower P. Patient-centredness: a conceptual framework and a review of the empirical literature. Soc Sci Med 2000; 51: 108723.

30. Bergström S and Goodburn E. The role of traditional birth attendants in the reduction of maternal mortality. Stud Serv Org Policy 2001; 17: 77-19. 
31. De Brouwere V and Van Lerberghe W. Les besoins obstétricaux non couverts. L'Harmattan, Paris, France, 1998, 229p.

32. Quéniart A. La technologie: une réponse à l'insécurité des femmes? In: Saillant $F$ and O'Neill M (Eds.). Accoucher Autrement: Repères sur les Aspects Historiques, Sociaux et Culturels sur la Grossesse et l'Accouchement au Québec. Les Editions coopératives Albert Saint Martin de Montréal, 1987, 212-281.

33. Browne FJ and Aberd. Antenatal care and Maternal Mortality. Lancet 1932; July 2: 14.

34. Reynolds FN. Letter. Lancet 1934; December: 2.
35. Maine D Rosenfield, A Mccarthy, J Kamara, A., and Lucas, A.O. Safe Motherhood Programs: Options and Issues. New-York: Columbia University, 1991.

36. De Brouwere V, Tonglet $\mathrm{R}$ and Van Lerberghe $\mathrm{W}$. Strategies for reducing maternal mortality in developing countries: what can we learn from the history of western countries? Trop Med Inter Health 1998; 3(10): 771-811. 